\title{
Synthesis of Carbon dots-based Fluorescent Probe for the High Selective Detection of Mercury Ions
}

\author{
Li Song*, Yanyan Cui \\ of Sciences, Beijing 100049, China \\ *songli14@mails.ucas.ac.cn
}

College of Materials Science and Opto-Electronic Technology, University of Chinese Academy

ABSTRACT: Fluorescent carbon dots (C-dots) were synthesized by one pot hydrothermal treatment of garlic juice at $180{ }^{\circ} \mathrm{C}$ for $7 \mathrm{~h}$. The as-prepared C-dots

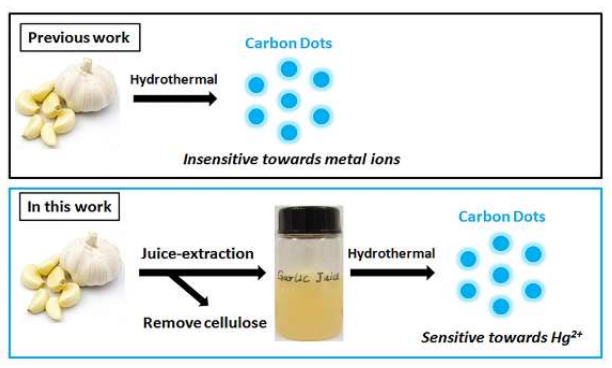
with an average diameter of $2.13 \pm 0.71$ $\mathrm{nm}$ can be well dispersed, and show absinthe fluorescence with a quantum yield of $8.9 \%$ in water. The C-dots were fully characterized by TEM, XPS, XRD, and FTIR, respectively. Additionally, the as-prepared C-dots reveal nearly nontoxic to SW480 cells and can be used for cell imaging. The water solution of C-dots show sensitivity to $\mathrm{pH}$ values and metal ions, and also have a high selectivity to the $\mathrm{Hg}^{2+}$ ion among other transition metal ions, and achieve a high sensitive detection with the detection limit of $0.45 \mu \mathrm{M}$. The fluorescent $\mathrm{C}$-dots are expected to be useful for the evaluation of mercury ions in environmental water system.

Keywords: Fluorescent carbon dots, hydrothermal treatment, characterization, cell imaging, mercury ions, selective and sensitive detection

\section{Introduction}

Compared with common small-molecular fluorophore, the fluorescent carbon dots (C-dots) possess several superior photophysical and biological properties, such as the high photostability, facial preparation, excellent water solubility, interfacial activity, low cytotoxicity, and biocompatibility in vitro and in vivo.[1-7]

Therefore, the $\mathrm{C}$-dots have been intensively and extensively investigated in biochemical sensing, fluorescent probes,photocatalytictechnology, environment testing, 
and drug carriers.[8-16]

On the sensing of metal ions by C-dots based probes, the detection of $\mathrm{Hg}^{2+}$ is attracting great attention from the community. Mercury ions is considered a typical health hazard and show highly toxic for human liver and central nervous system, which results an exposure to high level of mercury ions can lead to cerebral injury and cerebral death.[17-19] Therefore, to develop a sensitive and selective detection method for $\mathrm{Hg}^{2+}$ is of great importance for environment protection and human health.[20, 21]

Garlic, a valuable natural product, is rich in nutrition, and can prevent tumor and cancer due to its containing an appreciable amount of germanium, selenium and sulfospecies.[22, 23] Abundant production of garlic as carbon source enables a large-scale preparation of C-dots, Zhao et al. has reported the S- and N- co-doped C-dots with blue fluorescence prepared by garlic bulblet.[24] In the meanwhile of considering eliminating the difficult decomposing process of cellulose in garlic, herein, we designed and synthesized novel garlic-based C-dots via hydrothermal synthesis method by using garlic juice. Interestingly, the $\mathrm{C}$-dots from garlic juice have unique surface groups, which possess complete different metal ions binding property compared with reported garlic C-dots. The C-dots with the specific recognition ability can be utilized as an effective probe for mercury ions in water medium.[25-27]

\section{Experimental}

\subsection{Chemicals and materials}

Ultrapure water was made from ultrapure water purifier (Mini-Q). Garlics were purchased from supermarket. All of the metal-salt were purchased from Sigma-Aldrich. CCK-8 kit was purchased from BOSTER. Dulbecco's Modified Eagle's Medium (DMEM) and fetal bovine serum (FBS) were obtained from Gibco. SW480 cell line was obtained from Cell Resourcem Center, IBMS, CAMS/ PUMS. 

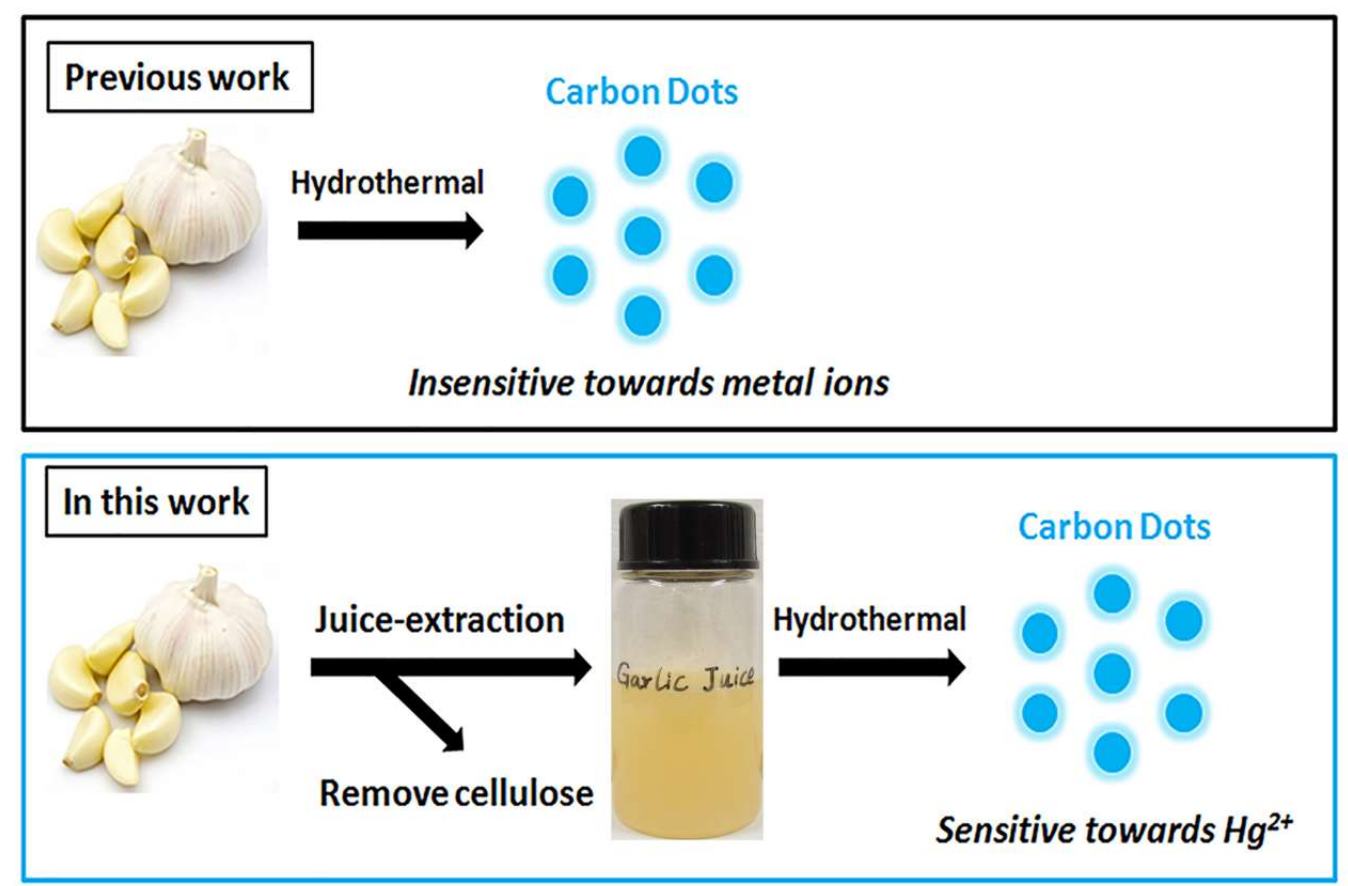

Scheme 1. Schematic representation of preparing C-dots by hydrothermal treatment of garlic.

\subsection{Instrument and characterization.}

All fluorescent measurements were performed on a Flouromax-4 spectrofluorometer (HORIBA JobinYvon Inc.) with excitation slit set at $25 \mathrm{~nm}$ band passes in $1 \mathrm{~cm} \times 1 \mathrm{~cm}$ quartz cell. In addition, UV-Vis absorption was characterized on a UV5800 spectrophotometer. The morphology and microstructure of the C-dots were examined by transmission electron microscopy (TEM) on JEM-1200EX electron microscopy with an accelerating voltage of $100 \mathrm{kV}$. For TEM characterization, one drop of C-dots suspension was deposited on a carbon-coated copper grid and dried at room temperature. The optical densities was measured on UV-vis spectra were obtained on a UV5800 spectrophotometer. The FTIR spectra were recorded on an IFS 66V/S (Bruker) IR spectrometer in the range of $600-4000 \mathrm{~cm}^{-1}$. X-ray photoelectron spectroscopy (XPS) analysis was measured on an ESCALAB MK II X-ray photoelectron spectrometer using patterns were obtained using $\mathrm{Cu} K \alpha$ radiation $(\mathrm{k}=1.54056 \AA) . \mathrm{Mg}$ as the exciting source. X-Ray. 


\subsection{Preparation of luminescent carbon dots.}

The skinless garlics were mashed to paste using a mortar and a pestle, the juice was squeezed out from it, and then pure water was mixed into the juice by the ratio of 4:5. Following, $5 \mathrm{ml}$ of the carbon source and $12 \mathrm{ml}$ ultrapure water were added into Teflon equipped stainless steel autoclave and then the mixture was heated in a constant temperature and humidity drying box at $180{ }^{\circ} \mathrm{C}$ for 7 hours, timing in line with the procedure of the reactor but not as soon as the Ptfe autoclave was put into the drying box. When the hydrothermal reaction finished, the autoclave was cooled down naturally and about $15 \mathrm{ml} \mathrm{C}$-dots solution was obtained by this way. Finally, the as-prepared C-dots original solution was purified for about 7 hours totally using a dialysis bag in a Bunsen beaker of $1000 \mathrm{ml}$ containing $800 \mathrm{ml}$ ultrapure water. The purified C-dots solution was dried at $60^{\circ} \mathrm{C}$, and then at $80^{\circ} \mathrm{C}$ in a vacuum drying oven.

2.4 Sensitivity Detection for $\mathrm{pH}$ values.

PL intensity changes of the obtained C-dots in aqueous solution were detected after they were adjusted to different $\mathrm{pH}$ values to discover the stability of $\mathrm{C}$-dots in internal environment of human. The diluted $\mathrm{C}$-dots aqueous solution, $10^{-1}$ times than the original, was adjusted to be $\mathrm{pH} 2, \mathrm{pH} 3, \mathrm{pH} 4, \mathrm{pH} 5, \mathrm{pH} 6, \mathrm{pH} 7, \mathrm{pH} 8, \mathrm{pH} 9, \mathrm{pH} 10, \mathrm{pH} 11, \mathrm{pH} 12$ using phosphate buffer by $\mathrm{pH}$ value card. The diluted $10^{-1}$ times $\mathrm{C}$-dots aqueous solution, $\mathrm{pH}$ values of which have been adjusted, were mixed well and placed for about 30 minutes at a room temperature, then mixed again and their PL intensities were examined immediately by a fluorescence spectrophotometer.

2.5 Cell culture, Cytotoxicity assay and Cell imaging.

The SW480 cells were maintained in DMEM /high glucose $(1 \times)$ medium supplemented with FBS of $10 \%(\mathrm{v} / \mathrm{v})$ at $37{ }^{\circ} \mathrm{C}$ in $5 \% \mathrm{CO}_{2}$ humidified atmosphere. Exponentially growing cells were dissociated with $0.25 \%$ Trypsin-EDTA $(1 \times)$ cell dissociation medium (GIBCO).

The cytotoxicity of C-dots towards SW480 cells was evaluated by the CCK-8 assay. Briefly the SW480 cells were seeded into a 96 -well plate for $100 \mu \mathrm{L}$ per well for $24 \mathrm{~h}$ at $37^{\circ} \mathrm{C}$. After the culture medium was removed, the medium containing $\mathrm{C}$-dots with different concentrations $(2 \mathrm{mg} / \mathrm{ml}-0.25 \mathrm{mg} / \mathrm{ml})$ was added into subsequently. The cells 
were then incubated for another $24 \mathrm{~h}$. After that, CCK-8 solution, in the volume of $10 \mu \mathrm{L}$ per well, was added to each well and incubated at $37^{\circ} \mathrm{C}$ for $1 \mathrm{~h}$. The absorbances were measured at $450 \mathrm{~nm}$ by the Enzyme standard instrument.

Following a bioimaging observing was conducted. The SW480 cells digested by the $0.25 \%$ Trypsin-EDTA $(1 \times)$ were plated in glass bottomed culture dishes(Mat Tek) and cultured for $24 \mathrm{~h}$, then the cell culture medium in the dishes were removed out of them, the remainder cells were washed for 3 times with PBS (pH 7.3), after that, $1 \mathrm{ml} \mathrm{C-dots}$ aqueous solution, of which the concentration was $1 \mathrm{mg} / \mathrm{ml}$, and $1 \mathrm{ml}$ cell culture medium without FBS were added to different dishes, control group and experimental group respectively, then they were incubated for another $4-6 \mathrm{~h}$ in the cell culture incubator. When the dishes cultured cells were carried out, the culture medium in them were removed as well, the remainder cells were washed for 1 time, and then $1 \mathrm{ml} 4 \%$ paraformaldehyde (sigma) was added to respectively. The dishes were placed in $4{ }^{\circ} \mathrm{C}$ for $30 \mathrm{~min}$ to fix the state of cells. At last, the cells fixed well in dishes can be observed by an NIKON TE2000 inverted fluorescence microscope system.

2.6 Quantum yield.

Using the below equation, the QY of the as-prepared C-dots, by measuring the fluorescence intensity in aqueous dispersion, can be calculated,

$$
\mathrm{Q}_{C-d o t}=\mathrm{Q}_{\mathrm{R}} \bullet \frac{I_{C-d o t}}{I_{R}} \bullet \frac{A_{R}}{A_{C-d o t}}
$$

In this equation, $\mathrm{Q}$ is the quantum yield of our sample and $\mathrm{I}$ is the measured intensity of luminescent spectra. A is the optical density at exited wavelength. QY was measured choosing quinine sulfate in $0.05 \mathrm{M}$ sulfuric acid solution (literature quantum yield $54 \%$ at $310 \mathrm{~nm}$ ) as a standard for C-dots. The subscript "R" refers to standard with known quantum yield and "C-dot" for the sample in this equation. In order to minimize reabsorption effects, absorbance of the C-dots solution in the $10 \mathrm{~mm}$ fluorescence cuvette was kept $\leq 0.05$ at the excitation wavelength $(400 \mathrm{~nm})$.

2.7 Detection as the sensing probe of the obtained C-dots for metal ions and $\mathrm{Hg}^{2+}$ ion. Compounding a variety of metal ion aqueous solutions $\left(\mathrm{Ni}^{2+}, \mathrm{Fe}^{2+}, \mathrm{Fe}^{3+}, \mathrm{Na}^{+}, \mathrm{Cu}^{2+}\right.$, $\left.\mathrm{Co}^{2+}, \mathrm{Ba}^{2+}, \mathrm{Cd}^{2+}, \mathrm{Mn}^{2+}\right)$, the concentration of which were all $5 \mathrm{mM}$, and the diluted $\mathrm{C}$ - 
dots aqueous solution, $10^{-1}$ times than the original, was mixed with 16 kinds of the precompounded metal ions of $5 \mathrm{mM}$ with the ratio of 1:9 respectively, the intermixtures were mixed well and placed for about 30 minutes at a room temperature, then mixed again and their PL intensities were examined immediately by a fluorescence spectrophotometer.

2.8 Sensitive detection for $\mathrm{Hg}^{2+}$ ion.

$\mathrm{Hg}^{2+}$ ion aqueous solutions with a certain concentration gradient from $5 \mathrm{mM}$ to $0 \mathrm{mM}$ were compounded firstly, then mixed with the diluted C-dots aqueous solution, $5 \times 10^{-1}$ times than the original with the ratio of 1:9 respectively, following the intermixtures were mixed well and placed for about 30 minutes at a room temperature, then mixed again and their PL intensities were examined immediately by a fluorescence spectrophotometer.

\section{Results and discusion}

3.1 Examinations of the properties of the as-prepared C-dots

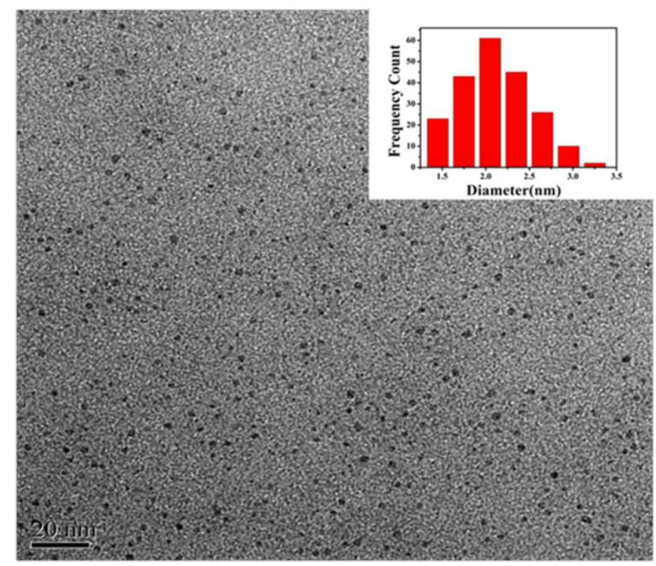

Figure 1. the TEM image of C-dots, scale bar: $10 \mathrm{~nm}$ (the inset was histograms of the particle size distribution of the as-prepared C-dots from 210 counts);

The morphology and size of the synthesized C-dots were investigated by TEM.

Figure 1 shows TEM image of the as-prepared C-dots combined with the corresponding particle size distribution histograms (Figure 1, inset). The results indicate that the diameters of C-dots are diameter of $2.13 \mathrm{~nm}$. The TEM image also reveals that the $\mathrm{C}$ - 

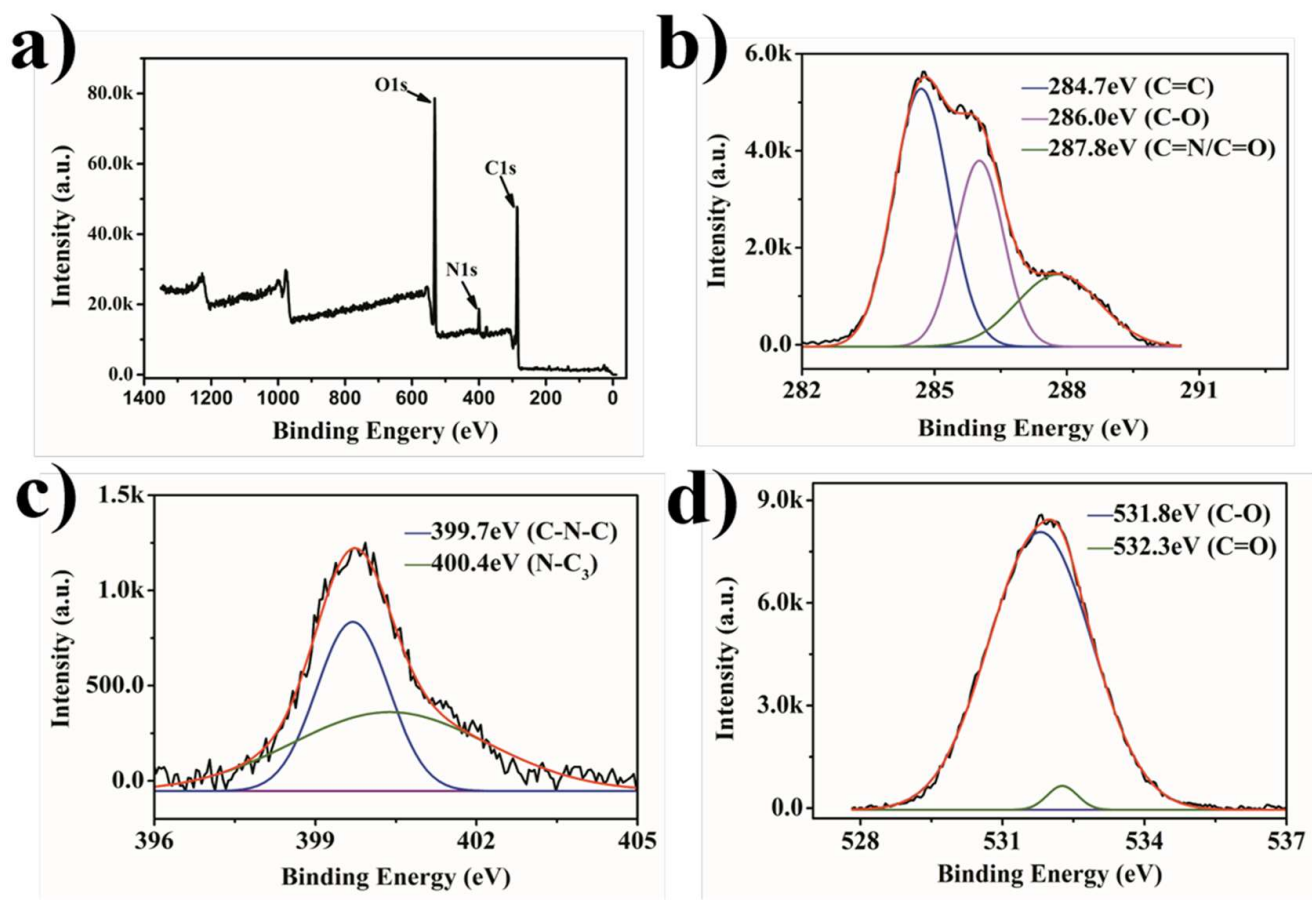

Figure 2. a) XPS survey spectra; b) C1s spectra; c) O1s spectra; d) N1s spectra

dots are almost spherical and monodispersed with a narrow size distribution[28]. Cdots were also characterized by X-ray diffraction (XRD) to describe the chemical nature of the C-dots. The XRD pattern of the C-dots (Figure S1) showed a broad amorphous peak at $2 \theta=22.5^{\circ}$, which clearly indicates the amorphous nature of the as-prepared C$\operatorname{dots}[29]$.

The X-ray photoelectron spectroscopy (XPS) analysis was performed to investigate the overall composition and the surface elemental analysis of the CDs as shown in Figure 2. The XPS survey spectra (shown in Figure 2a) reveals three peaks at 285.08eV, $399.74 \mathrm{eV}$, and $531.93 \mathrm{eV}$, which are attributed to $\mathrm{C}_{1 \mathrm{~s}}, \mathrm{~N}_{1 \mathrm{~s}}$ and $\mathrm{O}_{1 \mathrm{~s}}$, and the ratio of $\mathrm{C}, \mathrm{O}$ and $\mathrm{N}$ in the $\mathrm{C}$-dots are to be $63.06 \%, 29.92 \%$ and5.435\% (shown in Figure 2a), respectively.[30-32] The $\mathrm{C}_{1 \mathrm{~s}}$ spectra (Figure $2 \mathrm{~b}$ ) shows four peaks at $284.7 \mathrm{eV}, 285.9 \mathrm{eV}$, 286.0eV, $287.4 \mathrm{eV}$, which are attributed to $\mathrm{C}-\mathrm{C}, \mathrm{C}-\mathrm{N}, \mathrm{C}-\mathrm{O}$, and $\mathrm{C}=\mathrm{N} / \mathrm{C}=\mathrm{O}$ bands in $\mathrm{C}-$ dots. The $\mathrm{O}_{1 \mathrm{~s}}$ spectra (Figure 2c) exhibits two peaks at 531.1 and $532.1 \mathrm{eV}$, which are attributed to $\mathrm{C}=\mathrm{O}$ and $\mathrm{C}-\mathrm{OH} / \mathrm{C}-\mathrm{O}-\mathrm{C}$ bands in $\mathrm{C}$-dots. The $\mathrm{N}_{1 \mathrm{~s}}$ spectra (Figure $2 \mathrm{~d}$ ) shows two peaks at $399.3 \mathrm{eV}$ and $401.6 \mathrm{eV}$, which are attributed to the $\mathrm{C}-\mathrm{N}$ and $\mathrm{C}=\mathrm{N}$ bands in 
C-dots[33, 34]. It is not difficult to discover that the as- prepared C-dots have a more $\mathrm{C}=\mathrm{N}$ band on the surface than the $\mathrm{C}$-dots synthesied using garlic as the direct carbon source[24]. These results indicate that the local structure of the C-dots is composed of a series of $\mathrm{CN}$ and $\mathrm{CO}$ units, which contain a large number of unsaturated chemical bonds.

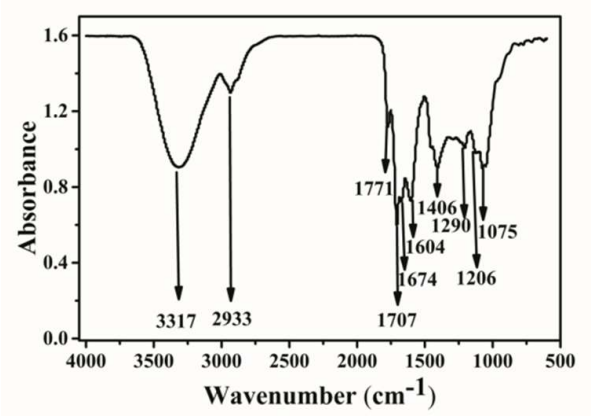

Figure 3. the FTIR spectrum of the as-prepared C-dots

To further identify the functional groups existing in C-dots, FTIR spectroscopy was studied[33]. A broad peak centering at $3317 \mathrm{~cm}^{-1}(\mathrm{v}-\mathrm{O}-\mathrm{H})$ and a should peak at $2933 \mathrm{~cm}^{-1}(\mathrm{v}-\mathrm{C}-\mathrm{H})$ reveal the existence of hydroxyl and alkanes groups on the surfaces of C-dots (shown in Figure 3), the characteristic absorptions at $1771 \mathrm{~cm}^{-1}$ and $1707 \mathrm{~cm}^{-}$ 1, demonstrate the existences of $-\mathrm{C}=\mathrm{O}$ groups. The detection of $V \mathrm{c}=\mathrm{c}$ vibration skeletons at about $1674 \mathrm{~cm}^{-1}$ indicates the existence of $-\mathrm{C}=\mathrm{C}$ groups on the surfaces of the $\mathrm{C}$-dots . Moreover, some peaks at $1604 \mathrm{~cm}^{-1}, 1406 \mathrm{~cm}^{-1}$ and $1290 \mathrm{~cm}^{-1}$, reveal that the C-dots contain the groups of $-\mathrm{N}-\mathrm{H},-\mathrm{C}-\mathrm{H},-\mathrm{C}-\mathrm{O}$, and the peaks at about $1206 \mathrm{~cm}^{-1}$ and 1075 $\mathrm{cm}^{-1}$ suggest the existences of $-\mathrm{C}-\mathrm{O} /-\mathrm{C}-\mathrm{O}-\mathrm{C}$ groups. These results further confirm that the existence of $-\mathrm{COOH},-\mathrm{OH},-\mathrm{NH}_{2}$, which is in accord with the results of XPS.

The morphology, size of the as-prepared C-dots and series functional groups on the surface of the C-dots endow the C-dots excellent optical properties and water solubility. Furthermore, the functional groups can provide accepting electron groups, including $\mathrm{C}=\mathrm{N},-\mathrm{C}=\mathrm{O}$ and $-\mathrm{COOH}$ in charge-transfer reactions between them and electrondonating groups to realize sensing function, and the sensing property of the obtained $\mathrm{C}$ dots will be in the following researches.To realize the optical properties of the asprepared C-dots, the UV-vis absorption spectrum and photoluminescent spectra of the 

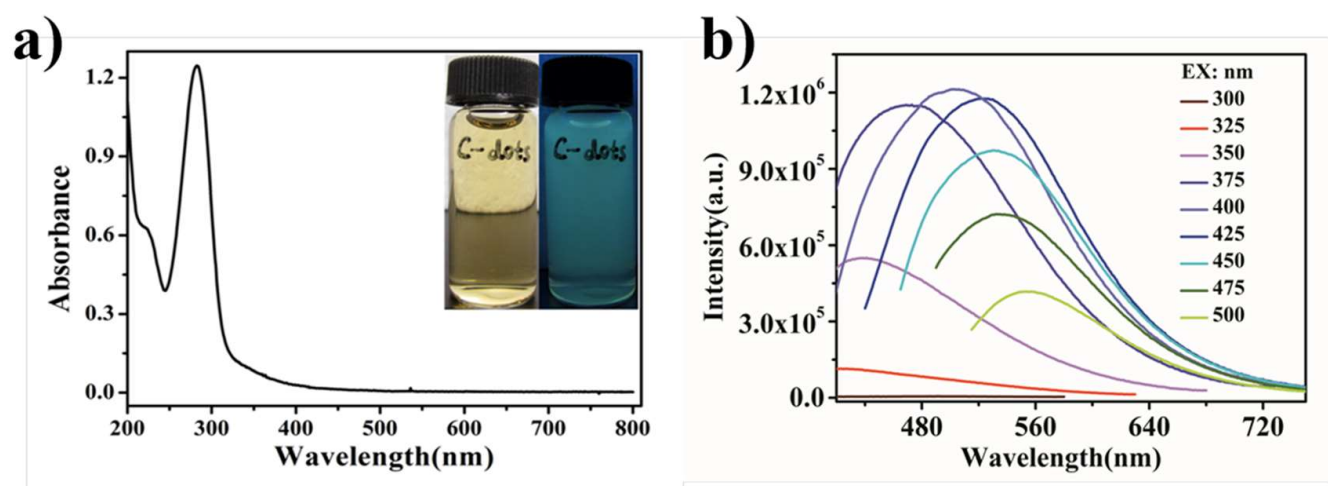

Figure 4. a) UV-visible absorption spectrum of C-dots; inset, under bright light (left) and UV light (right), b) emission spectra of the as prepared C-dots at different excitation spectra

diluted aqueous solution of C-dots were measured respectively. UV-visible absorption of the C-dots aqueous solution could be seen from Figure 4a) clearly, showing the as prepared C-dots have a weak absorption band at $\sim 300 \mathrm{~nm}$, which is attributed to the $\mathrm{n}-$ $\pi^{*}$ electron transition.[36-38] In addition, the diluted aqueous solution of the asprepared C-dots can be excited at $400 \mathrm{~nm}$ wavelength exciting light to obtain a strongest absorption peak with a $500 \mathrm{~nm}$ emission wavelength (as shown in Figure 4b), which is very stable, when the $\mathrm{C}$-dots aqueous solution was prepared at $37{ }^{\circ} \mathrm{C}$ from the initial reaction solution, it also can emit absinthe fluorescence while being exposed to an ultraviolet lamp unit at $365 \mathrm{~nm}$, in comparison to non-blooming aqueous solution of Cdots under sun-light, which conformed the formation of fluorescent production, being shown in Figure. 1a. The QY of the as-prepared C-dots was estimated to be 8.9\%.[30] C-dots are considered much safer for fluorescent probes in biological application, and they are also sensitive for metal ions detections and $\mathrm{pH}$ responses in microenvironment of organism tissues. $[39,40]$ At the same time, C-dots are nanometer size fluorescent nanomaterials, they are able to pass into cells,which make them to be applied for cell imaging, and then drug loading[30, 41, 42]. At present, much effort has been put into developing green approaches to prepare fluorescent C-dots. Some raw materials have been used as carbon sources to synthesize C-dots, such as activated carbon, natural 
products and so on[43, 44].

a)

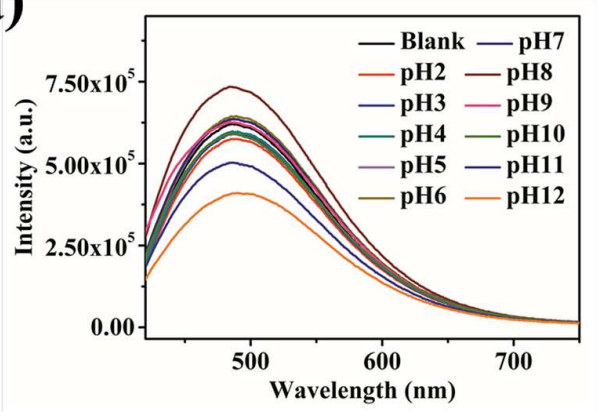

b)

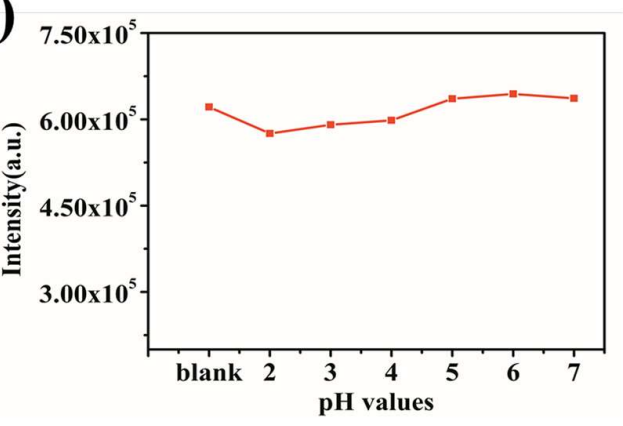

Figure 5. a) Sensitivity of the as-prepared C-dots aqueous solution toward different $\mathrm{pH}$ values; b) line graph of the intensity of C-dots solution quenched at different $\mathrm{pH}$

Moreover, by detecting changes in fluorescence intensity caused by $\mathrm{pH}$ values having a range of 2-12, we can also judge the stability of C-dots in internal environment by PL intensity quenching of $\mathrm{C}$-dots aqueous solution having different $\mathrm{pH}$ values. From Figure 5a, the strongest PL intensity is $\mathrm{pH} 8$ of the $\mathrm{C}$-dots solution, a significant fluorescence enhancing phenomenon, when the $\mathrm{pH}$ values is $\mathrm{pH} 2, \mathrm{pH} 3, \mathrm{pH} 4$. As being illustration, the spectrum was detected showing there are a series of function groups at the surface of the C-dots, such as - $\mathrm{COOH},-\mathrm{OH},-\mathrm{NH}_{2}$, and the fluorescence quenching may due to electron transfer between these groups of $\mathrm{C}$-dots at different $\mathrm{pH}$ values[33, 34, 45]. A line graph of Figure 5b shows PL intensities changing trend at $\mathrm{pH} 2-\mathrm{pH} 7$, the changing is slight, from which a conclusion can be obtained that the C-dots are stable in human internal environment of $\mathrm{pH} 2-\mathrm{pH} 7[46]$.

Besides, by evaluating the cytotoxicity of the as-prepared C-dots, the cell viabilities are all $\geq 80 \%$ when the concentration of the as-prepared C-dots is $\leq 1 \mathrm{mg} / \mathrm{ml}$ from Figure $\mathrm{s} 2$, indicating the as-prepared C-dots has a low cytotoxicity to SW480 cell in vitro, consequently this kind of C-dots are able to be used for biological organism researches, such as cell imaging and biosensing of metal ions in vitro[44, 47, 48]. Sequentially, while the SW480 cell they were exposed at a UV excitation light, and the overly of their imaging in bright-field and UV excitation light respectively was shown in Figure 6c[4, 49]. Therefore, the as-prepared C-dots having passed into cancer cells are able to emit 
absinthe fluorescence stably when they were exposed at UV-light, indicating an application as a kind of nanoparticles to realize the sustainable observation of SW480 cells morphology.

a)

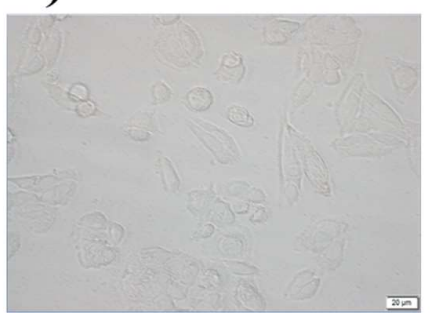

b)

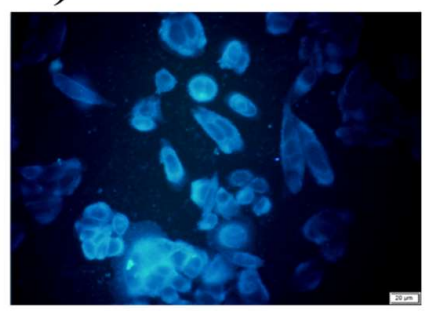

c)

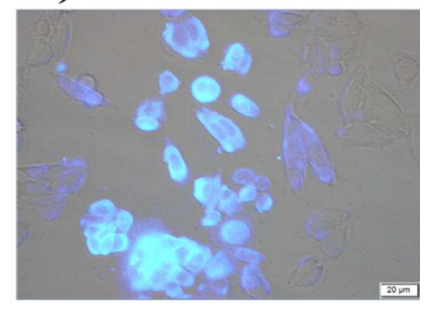

Figure 6. a) SW480 cell imaging in bright-field; b)SW480 cell PL imaging obtained with a $365 \mathrm{~nm}$ excitation wavelength; c) the overly of a) and b).Scale bar $=20 \mu \mathrm{m}$.

3.2 Detection as the sensing probe of the as-prepared C-dots for metal ions and $\mathrm{Hg}^{2+}$ ion.

By detecting changes in fluorescence intensity caused by external physical or chemical stimuli, which may be metal ions, such as $\mathrm{Ni}^{2+}, \mathrm{Mg}^{2+}, \mathrm{Fe}^{2+}, \mathrm{Ca}^{2+}, \mathrm{Hg}^{2+}, \mathrm{Mn}^{2+}$, $\mathrm{Na}^{+}, \mathrm{Cu}^{2+}, \mathrm{Mn}^{2+}, \mathrm{Co}^{2+}, \mathrm{Cd}^{2+}$, a selectivity of the C-dots solution for metal ions with different charges can be obtained[28, 50].

Concretely, by the detection for 11 kinds metal ions at a concentration of $5 \mathrm{mM}$ respectively, PL intensity of C-dots solutions quenched by every metal ion which was used here all come to change, and as compared with other metal ions, the fluorescence of $\mathrm{C}$-dots solution mixed with $\mathrm{Hg}^{2+}$ ion is quenched largely, which shows the most obvious quenching effect on the PL intensity from the fluorescent intensity spectra shown in Figure 7a, moreover, from Figure $7 \mathrm{~b}$, the value of F-F $\mathrm{F}_{0}$ about C-dots solution quenched by $\mathrm{Hg}^{2+}$ illustrates the changes of PL intensities between the quenched C-dots ultrapure

water solution and the blank group, besides, there is also a biggest change of $\mathrm{Hg}^{2+}$ among the other quenched C-dots solutions by the other metal ions[9, 12, 51]. Following, Figure 7c is the quenched fluorescence spectra of $\mathrm{Hg}^{2+}$ at different concentrations, it is observed that the quenched degree of $\mathrm{C}$-dots solution by $\mathrm{Hg}^{2+}$ is 
a)

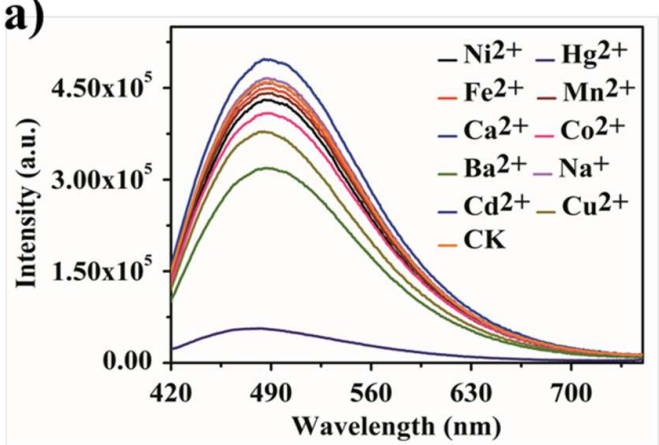

c)

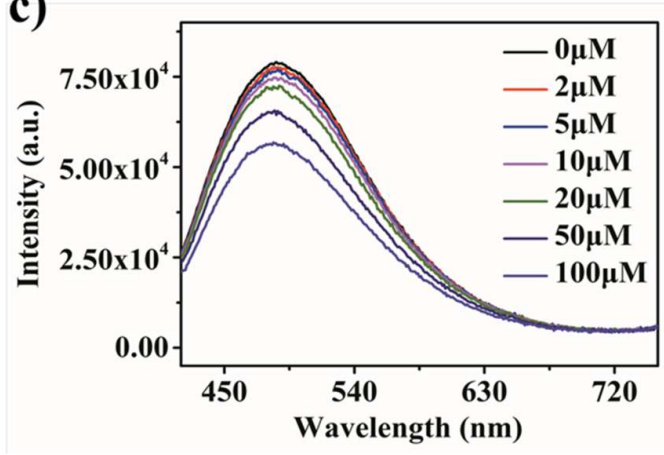

b)

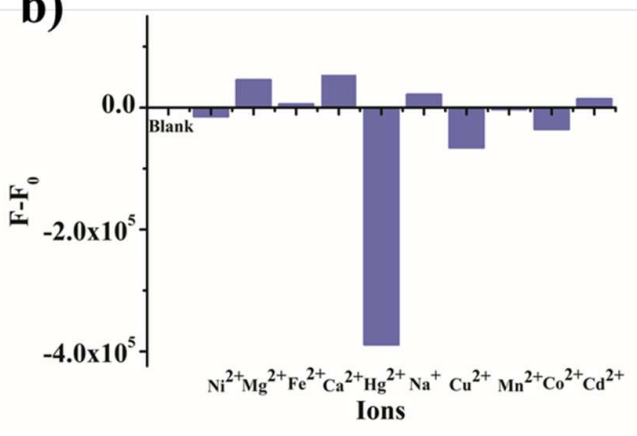

d)

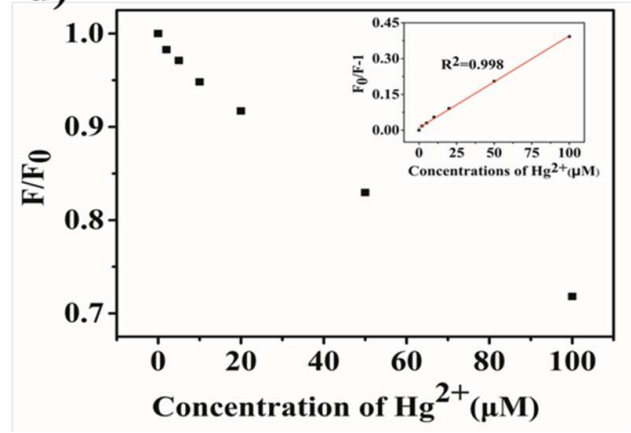

Figure 7. a) spectra of fluorescence being quenched for the addition of different metal ions; b) histogram of $\mathrm{F}_{-} \mathrm{F}_{0}$ from different metal ions quenching $\mathrm{C}$-dots solution; c) spectra of quenched fluorescence of C-dots solution by $\mathrm{Hg}^{2+}$ at different concentrations; d) Sensitivity of $\mathrm{Hg}^{2+}$ detection: $\mathrm{F} / \mathrm{F}_{0}$ and a fitting line for calculating the limit

becoming more and more obvious following a rising trend of the $\mathrm{Hg}^{2+}$ concentrations. Figure $7 \mathrm{~d}$ showed the $F / F_{0}$ values of the as-prepared $\mathrm{C}$-dots solution treated with a concentration gradient of $\mathrm{Hg}^{2+}$ ions, indicating the quenching degree compared with reference solution, and its detecting limit is $0.45 \mu \mathrm{M}$ calculated by the formula of $y=0.004 x+0.01$ from the fitting line shown in the inset graph of Figure $7 d, R^{2}=0.998$. In conclusion, water solution of the as-prepared C-dots has good selectivity and sensitivity to $\mathrm{Hg}^{2+}$ when it is used to detecting metal ions as a sensing probe[16, 52]

\section{Conclusions}

In summary, we developed a green, concise and low-cost method to synthesize photoluminescent C-dots using the garlic as the precursor by hydrothermal treatment. From the results of characterization, the as-prepared C-dots are a kind of nanoparticle 
having an average diameter of $2.13 \pm \mathbf{0 . 7 1} \mathrm{nm}$ and a series functional groups including some unsaturated groups which are able to obtain electrons, otherwise, the fluorescence of the as prepared C-dots aqueous solution can be quenched by being adjusted with different $\mathrm{pH}$ values, giving rise to a strongest fluorescence quenching degree of $\mathrm{pH} 12$ and an enhanced fluorescence intensity of $\mathrm{pH}$ 8. These results illustrate the C-dots solution is stable in human internal environment with a $\mathrm{pH}$ rang of 2 to 7 . The asprepared C-dots solution can emit absinthe-green fluorescence under UV-light by good fluorescent properties. In additional, this kind of C-dots having passed into cancer cells are able to emit absinth fluorescence stably when they are exposed to UV light, then they were used for cell imaging to observe the morphology of SW480 cell sustainably and can be applied as drug carriers to load drugs for its small particle size and nontoxicity. The fluorescence can be quenched by $\mathrm{Hg}^{2+}$ from $5 \mathrm{mM}$ to $10 \mathrm{nM}$ with a detecting limit is $0.45 \mu \mathrm{M}$ at a concentration rang of $0 \mu \mathrm{M}-100 \mu \mathrm{M}$, which illustrate the sensitivity and selectivity of the as-prepared C-dots for $\mathrm{Hg}^{2+}$, resulting the C-dots synthesized by one pot hydrothermal treatment can be used as fluorescent probe to detecting $\mathrm{Hg}^{2+}$ in natural environments and human internal environments having a high level of $\mathrm{Hg}^{2+}$.

\section{AKNOWLEDGEMENTS}

This work was supported by the State Key Project of Fundamental Research (Grants 2014CB931900 and 2012CB932504), "Hundred Talents Project" and Scientific Research Equipment Project of the Chinese Academy of Sciences. Then thanks are due to L. Lin for influences for preparing the garlic juice from garlic bulblet.

\section{NOTES AND REFERENCES}

Key Laboratory of Optoelectronic Devices and Systems of Ministry of Education and Guangdong Province, College of Optoelectronic Engineering, Shenzhen University, Shenzhen 518060, China.E-mail: bliu@szu.edu.cn (B. Liu) 
College of Materials Science and Opto-electronic Technology, University of Chinese Academy of Sciences, Beijing 100049, China. Fax: 86-10-88256840; Tel: 86-1088256840; E-mail: liuxf@ucas.ac.cn (X. Liu);

\section{Reference}

1. Esteves da Silva, J. C. G.; Gonçalves, H. M. R., Analytical and bioanalytical applications of carbon dots. TrAC Trends in Analytical Chemistry 2011, 30, (8), 1327-1336.

2. Strauss, V.; Margraf, J. T.; Dolle, C.; Butz, B.; Nacken, T. J.; Walter, J.; Bauer, W.; Peukert, W.; Spiecker, E.; Clark, T.; Guldi, D. M., Carbon nanodots: toward a comprehensive understanding of their photoluminescence. Journal of the American Chemical Society 2014, 136, (49), 9.

3. Yang, X.; Zhuo, Y.; Zhu, S.; Luo, Y.; Feng, Y.; Dou, Y., Novel and green synthesis of highfluorescent carbon dots originated from honey for sensing and imaging. Biosensors and Bioelectronics 2014, 60, 7.

4. Zhuo, Y.; Miao, H.; Zhong, D.; Zhu, S.; Yang, X., One-step synthesis of high quantum-yield and excitation-independent emission carbon dots for cell imaging. Materials Letters 2015, 139, 4.

5. Athinarayanan, J.; Periasamy, V. S.; Alhazmi, M.; Alshatwi, A. A., Synthesis and biocompatibility assessment of sugarcane bagasse-derived biogenic silica nanoparticles for biomedical applications. Journal of Biomedical Materials Research Part B: Applied Biomaterials 2017, 105, (2), 10.

6. Niu, N.; Ma, Z.; He, F.; Li, S.; Li, J.; Liu, S.; Yang, P., Preparation of Carbon Dots for Cellular Imaging by the Molecular Aggregation of Cellulolytic Enzyme Lignin. Langmuir : the ACS journal of surfaces and colloids 2017, 33, (23), 5786-5795.

7. Qureshi, A.; Kang, W. P.; Davidson, J. L.; Gurbuz, Y., Review on carbon-derived, solid-state, micro and nano sensors for electrochemical sensing applications. Diamond and Related Materials 2009, 18, (12), 20.

8. Chandra, S.; Pradhan, S.; Mitra, S.; Patra, P.; Bhattacharya, A.; Pramanik, P.; Goswami, A., High throughput electron transfer from carbon dots to chloroplast: a rationale of enhanced photosynthesis. Nanoscale 2014, 6, (7), 8.

9. Huang, H.; Li, H.; Wang, A. J.; Zhong, S. X.; Fang, K. M.; Feng, J. J., Green synthesis of peptide-templated fluorescent copper nanoclusters for temperature sensing and cellular imaging. The Analyst 2014, 139, (24), 6.

10. Gu, J.; Hu, D.; Wang, W.; Zhang, Q.; Meng, Z.; Jia, X.; Xi, K., Carbon dot cluster as an efficient "off-on" fluorescent probe to detect $\mathrm{Au}(\mathrm{III})$ and glutathione. Biosensors and Bioelectronics 2015, $68,8$.

11. Vikneswaran, R.; Ramesh, S.; Yahya, R., Green synthesized carbon nanodots as a fluorescent probe for selective and sensitive detection of iron(III) ions. Materials Letters 2014, 136, 4.

12. Li, X.; Zhang, S.; Kulinich, S. A.; Liu, Y.; Zeng, H., Engineering surface states of carbon dots to achieve controllable luminescence for solid-luminescent composites and sensitive Be2+ detection. Scientific Reports 2014, 4, (4976), 8.

13. Ma, Z.; Ming, H.; Huang, H.; Liu, Y.; Kang, Z., One-step ultrasonic synthesis of fluorescent N- 
doped carbon dots from glucose and their visible-light sensitive photocatalytic ability. New Journal of Chemistry 2012, 36, (4), 4.

14. Wang, J.; Ng, Y. H.; Lim, Y.-F.; Ho, G. W., Vegetable-extracted carbon dots and their nanocomposites for enhanced photocatalytic $\mathrm{H}_{2}$ production. RSC Advances 2014, 4, (83), 7.

15. Pierrat, P.; Wang, R.; Kereselidze, D.; Lux, M.; Didier, P.; Kichler, A.; Pons, F.; Lebeau, L., Efficient in vitro and in vivo pulmonary delivery of nucleic acid by carbon dot-based nanocarriers. Biomaterials 2015, 51, 12.

16. Mohapatra, S.; Sahu, S.; Sinha, N.; Bhutia, S. K., Synthesis of a carbon-dot-based photoluminescent probe for selective and ultrasensitive detection of $\mathrm{Hg}^{2+}$ in water and living cells. The Analyst 2015, 140, (4), 8.

17. Santos-Figueroa, L. E.; Moragues, M. E.; Climent, E.; Agostini, A.; Martinez-Manez, R.; Sancenon, F., Chromogenic and fluorogenic chemosensors and reagents for anions. A comprehensive review of the years 2010-2011. Chemical Society reviews 2013, 42, (8), 125.

18. Gonçalves, A. C.; Capelo, J. L.; Lodeiro, C.; Santos, A. A. D., A seleno-pyrene selective probe for $\mathrm{Hg} 2+$ detection in either aqueous or aprotic systems. Sensors and Actuators B: Chemical 2017, 239, 311-318.

19. Erdemir, S.; Yuksekogul, M.; Karakurt, S.; Kocyigit, O., Dual-channel fluorescent probe based on bisphenol A-rhodamine for $\mathrm{Zn} 2+$ and $\mathrm{Hg} 2+$ through different signaling mechanisms and its bioimaging studies. Sensors and Actuators B: Chemical 2017, 241, 230-238.

20. Ding, Y.; Wang, S.; Li, J.; Chen, L., Nanomaterial-based optical sensors for mercury ions. $\operatorname{Tr} A C$ Trends in Analytical Chemistry 2016, 82, 175-190.

21. Xiangfeng Guo, $\ddagger$ Xuhong Qian, ${ }^{*}, \dagger$ and Lihua Jia $\uparrow, \S$, A Highly Selective and Sensitive Fluorescent Chemosensor for Hg2+ in Neutral Buffer Aqueous Solution. J. AM. CHEM. SOC. 2004, 126, (8), 2.

22. Anassori, E.; Dalir-Naghadeh, B.; Pirmohammadi, R.; Hadian, M., Changes in blood profile in sheep receiving raw garlic, garlic oil or monensin. Journal of animal physiology and animal nutrition 2015, 99, (1), 19.

23. H.A.R.Suleria; M.S.Butt; N.Khalid; S.Sultan; A.Raza; M.Aleem; M.Abbas, Asian.Pac.J.Trop.Dis 2015, 5, (4), 8.

24. Zhao, S.; Lan, M.; Zhu, X.; Xue, H.; Ng, T. W.; Meng, X.; Lee, C. S.; Wang, P.; Zhang, W., Green Synthesis of Bifunctional Fluorescent Carbon Dots from Garlic for Cellular Imaging and Free Radical Scavenging. ACS applied materials \& interfaces 2015, 7, (31), 7.

25. Wang, M.; Yang, X.; Zhang, P.; Cai, L.; Yang, X.; Chen, Y.; Jing, Y.; Kong, J.; Yang, X.; Sun, F. L., Sustained Delivery Growth Factors with Polyethyleneimine-Modified Nanoparticles Promote Embryonic Stem Cells Differentiation and Liver Regeneration. Advanced science 2016, $3,(8), 13$.

26. Placek, L. M.; Keenan, T. J.; Li, Y.; Yatongchai, C.; Pradhan, D.; Boyd, D.; Mellott, N. P.; Wren, A. W., Investigating the effect of $\mathrm{TiO}_{2}$ on the structure and biocompatibility of bioactive glass. Journal of Biomedical Materials Research Part B: Applied Biomaterials 2016, 104, (8), 10.

27. Roberts, V. M.; Stein, V.; Reiner, T.; Lemonidou, A.; Li, X.; Lercher, J. A., Towards quantitative catalytic lignin depolymerization. Chemistry 2011, 17, (21), 5939-48.

28. Wang, W.; Li, Y.; Cheng, L.; Cao, Z.; Liu, W., Water-soluble and phosphorus-containing carbon dots with strong green fluorescence for cell labeling. Journal of Materials Chemistry B 2014, 2 , (1), 3 . 
29. A.Konwar; N.Gogoi; G.Majumdar; D.Chowdhury, Carbohyd.Polym 2015, 115, 7.

30. Fan, R.-J.; Sun, Q.; Zhang, L.; Zhang, Y.; Lu, A.-H., Photoluminescent carbon dots directly derived from polyethylene glycol and their application for cellular imaging. Carbon 2014, 71, 7.

31. Mehta, V. N.; Jha, S.; Singhal, R. K.; Kailasa, S. K., Preparation of multicolor emitting carbon dots for HeLa cell imaging. New Journal of Chemistry 2014, 38, (12), 9.

32. Tan, D.; Zhou, S.; Shimotsuma, Y.; Miura, K.; Qiu, J., Effect of UV irradiation on photoluminescence of carbon dots. Optical Materials Express 2014, 4, (2), 6.

33. Fu, C.; Qiang, L.; Liu, T.; Tan, L.; Shi, H.; Chen, X.; Ren, X.; Meng, X., Ultrafast chemical aerosol flow synthesis of biocompatible fluorescent carbon dots for bioimaging. Journal of Materials Chemistry B 2014, 2, (40), 6.

34. Nie, H.; Li, M.; Li, Q.; Liang, S.; Tan, Y.; Sheng, L.; Shi, W.; Zhang, S. X.-A., Carbon Dots with Continuously Tunable Full-Color Emission and Their Application in Ratiometric pH Sensing. Chemistry of Materials 2014, 26, (10), 98.

35. Fu, C.; Qiang, L.; Liu, T.; Tan, L.; Shi, H.; Chen, X.; Ren, X.; Meng, X., Ultrafast chemical aerosol flow synthesis of biocompatible fluorescent carbon dots for bioimaging. J. Mater. Chem. B 2014, 2, (40), 6978-6983.

36. Y.Y.Cui; Z.B.Hu; C.F.Zhang, X. F. L., Simultaneously enhancing up-conversion fluorescence and red-shifting down-conversion luminescence of carbon dots by a simple hydrothermal process $\dagger$. J.Mater.Chem.B 2014, 2, (40), 6.

37. Li, W.; Yue, Z.; Wang, C.; Zhang, W.; Liu, G., An absolutely green approach to fabricate carbon nanodots from soya bean grounds. RSC Advances 2013, 3, (43), 4.

38. Weng, C. I.; Chang, H. T.; Lin, C. H.; Shen, Y. W.; Unnikrishnan, B.; Li, Y. J.; Huang, C. C., One-step synthesis of biofunctional carbon quantum dots for bacterial labeling. Biosensors and Bioelectronics 2015, 68, 7.

39. Miao, P.; Han, K.; Tang, Y.; Wang, B.; Lin, T.; Cheng, W., Recent advances in carbon nanodots: synthesis, properties and biomedical applications. Nanoscale 2015, 7, (5), 10.

40. Li, M.; Gou, H.; Al-Ogaidi, I.; Wu, N., Nanostructured Sensors for Detection of Heavy Metals: A Review. ACS Sustainable Chemistry \& Engineering 2013, 1, 10.

41. Yu, C.; Li, X.; Zeng, F.; Zheng, F.; Wu, S., Carbon-dot-based ratiometric fluorescent sensor for detecting hydrogen sulfide in aqueous media and inside live cells. Chemical communications 2013, 49, (4), 3.

42. De, B.; Karak, N., A green and facile approach for the synthesis of water soluble fluorescent carbon dots from banana juice. RSC Advances 2013, 3, (22), 5.

43. M.Algarra; M.Perez-Martin; M.Cifuentes-Rueda; J.Jimenez-Jimenez; J. C.Esteves da Silva; T. J.Bandosz; E.Rodriguez-Castellon; J. T.Lopez Navarrete; J.Casado, Carbon dots obtained using hydrothermal treatment of formaldehyde. Cell imaging in vitro? Nanoscale 2014, 6, (15), 8.

44. S.Gome.de. Pedro; A.Salinas-Castillo; M.Ariza-Avidad; A.Lapresta-Fernandez; C.SanchezGonzalez; C. S.Martinez-Cisneros; M.Puyol; L. F.Capitan-Vallvey; J.Alonso-Chamarro, Microsystem-assisted synthesis of carbon dots with fluorescent and colorimetric properties for pH detection. Nanoscale 2014, 6, (11), 7.

45. Zhang, H.; Chen, Y.; Liang, M.; Xu, L.; Qi, S.; Chen, H.; Chen, X., Solid-phase synthesis of highly fluorescent nitrogen-doped carbon dots for sensitive and selective probing ferric ions in living cells. Analytical chemistry 2014, 86, (19), 7. 
46. Li, S.; Deng, H.; Cao, W.; Zhang, C.; Jin, S.; Xue, X.; Zhang, J.; Li, F.; Zou, G.; Liang, X. J., A fluorescent probe with restricted intramolecular rotation-induced emission for label-free detection of mercury ions. The Analyst 2014, 139, (13), 3369-72.

47. Zeng, Q.; Shao, D.; He, X.; Ren, Z.; Ji, W.; Shan, C.; Qu, S.; Li, J.; Chen, L.; Li, Q., Carbon dots as a trackable drug delivery carrier for localized cancer therapy in vivo. Journal of Materials Chemistry B 2016, 4, (30), 7.

48. Zhu, A.; Luo, Z.; Ding, C.; Li, B.; Zhou, S.; Wang, R.; Tian, Y., A two-photon "turn-on" fluorescent probe based on carbon nanodots for imaging and selective biosensing of hydrogen sulfide in live cells and tissues. The Analyst 2014, 139, (8), 1945-52.

49. Sun, Q.; Sun, X.; Ma, X.; Zhou, Z.; Jin, E.; Zhang, B.; Shen, Y.; Van Kirk, E. A.; Murdoch, W. J.; Lott, J. R.; Lodge, T. P.; Radosz, M.; Zhao, Y., Integration of nanoassembly functions for an effective delivery cascade for cancer drugs. Advanced materials 2014, 26, (45), 7.

50. Zhao, A.; Zhao, C.; Li, M.; Ren, J.; Qu, X., Ionic liquids as precursors for highly luminescent, surface-different nitrogen-doped carbon dots used for label-free detection of $\mathrm{Cu}^{2+} / \mathrm{Fe}^{3+}$ and cell imaging. Anlytica Chimica Acta 2014, 809, 6.

51. Wang, L.; Wang, Y.; Xu, T.; Liao, H.; Yao, C.; Liu, Y.; Li, Z.; Chen, Z.; Pan, D.; Sun, L.; Wu, M., Gram-scale synthesis of single-crystalline graphene quantum dots with superior optical properties. Nature communications 2014, 5, (5357), 9.

52. Yin, B.; Deng, J.; Peng, X.; Long, Q.; Zhao, J.; Lu, Q.; Chen, Q.; Li, H.; Tang, H.; Zhang, Y.; Yao, S., Green synthesis of carbon dots with down- and up-conversion fluorescent properties for sensitive detection of hypochlorite with a dual-readout assay. The Analyst 2013, 138, (21), 6551-7.

TOC

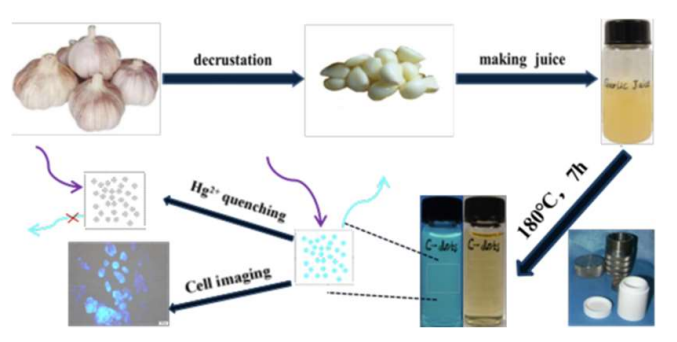

